\title{
PEDIATRIC ORIGINAL ARTICLE Longitudinal associations between television in the bedroom and body fatness in a UK cohort study
}

\author{
A Heilmann ${ }^{1}$, P Rouxel ${ }^{1,2}$, E Fitzsimons ${ }^{3}$, Y Kelly $^{1}$ and RG Watt ${ }^{1}$
}

\begin{abstract}
OBJECTIVE: To assess longitudinal associations between screen-based media use (television (TV) and computer hours, having a TV in the bedroom) and body fatness among UK children.

METHODS: Participants were 12556 children from the UK Millennium Cohort Study who were followed from age 7 to age 11 years. Associations were assessed between screen-based media use and the following outcomes: body mass index (BMI), fat mass index (FMI), and overweight.

RESULTS: In fully adjusted models, having a bedroom TV at age 7 years was associated with significantly higher BMI and FMI (excess BMI for boys $=0.29,95 \%$ confidence interval $(\mathrm{Cl})$ 0.06-0.52; excess BMI for girls $=0.57,95 \% \mathrm{Cl} 0.31-0.84$; excess $\mathrm{FMI}$ for boys $=0.20,95 \% \mathrm{Cl} 0.04-0.37$; excess FMI for girls $=0.39,95 \% \mathrm{Cl} 0.21-0.57$ ) and increased risk of being overweight (relative risk (RR) for boys $=1.21,95 \% \mathrm{Cl} 1.07-1.36$; RR for girls $=1.31,95 \% \mathrm{Cl} 1.15-1.48$ ) at age 11 years, compared with having no bedroom TV. Hours spent watching TV or digital versatile disks were associated with increased risk of overweight among girls only. Computer use at age 7 years was not related to later body fatness for either gender.

CONCLUSION: Having a TV in the child's bedroom was an independent risk factor for overweight and increased body fatness in this nationally representative sample of UK children. Childhood obesity prevention strategies should consider TVs in children's bedrooms as a risk factor for obesity.
\end{abstract}

International Journal of Obesity (2017) 41, 1503-1509; doi:10.1038/ijo.2017.129

\section{INTRODUCTION}

Screen-based media have a central role in the lives of today's children. As technology advances, children now have unparalleled access not only to television (TV) screens but also to computers, game consoles and mobile devices. ${ }^{1}$ In the United Kingdom, TV is still the most consumed medium among children aged 5-11 years, with gaming coming second. ${ }^{2,3}$

At the same time, rising childhood obesity levels are a national and global public health concern. ${ }^{4}$ In 2014/15, a third of 11-yearold children in England were overweight and almost a fifth were obese. $^{5}$ Ironically, while our screens have become flatter, our children have become fatter. Indeed, a relationship between TV viewing and overweight among children and adolescents has been repeatedly reported..$^{6-13}$ There is some evidence that a TV in the child's bedroom might exacerbate the problem. ${ }^{8,14,15}$ Potential pathways include snacking/eating calorie-dense foods while watching $\mathrm{TV}^{16-19}$ exposure to food advertising and product placement $^{16,17,20}$ and reduced or disrupted sleep. ${ }^{21-25}$ An association between screen time and reduced physical activity is often hypothesized but empirical evidence has been contradictory. ${ }^{12,26-28}$

UK research on screen use and overweight has so far been mainly cross-sectional and has focused on TV viewing as one of the several risk factors for overweight and obesity among young children, with some conflicting results. ${ }^{29-32}$ Residual confounding and reverse causality remain potential issues in the existing literature, and little is known about the role of computer games. Further, UK studies have so far relied mainly on body mass index (BMI) as the outcome variable, or overweight and obesity derived from BMI. However, using BMI alone is not the best way of assessing adiposity or body fatness, because it does not distinguish between fat mass and fat-free (lean) mass and can therefore be affected by either. The fat mass index (FMI) is a measure of fat mass (FM) adjusted for height (FM divided by height squared) that is not confounded by fat-free mass ${ }^{33}$ and is therefore a valuable additional indicator of body composition. In this study, we examine longitudinal associations between children's screen based media use at age 7 years and their BMI, FMI and overweight status at age 11 years while adjusting for a wide range of covariates.

\section{METHODS}

Data

We analyzed data from the UK Millennium Cohort Study (MCS). The MCS is a nationally representative, prospective cohort study that follows the lives of children born between September 2000 and January 2002 in the four countries of the United Kingdom. The sample is geographically clustered and stratified to overrepresent economically disadvantaged areas, areas with high proportions of people from ethnic minority backgrounds, and the three smaller countries of the United Kingdom. The MCS is designed and managed by the UK Centre for Longitudinal Studies (CLS) at the UCL Institute of Education. The data sets are fully anonymized and available for academic use from the UK Data Service.

Data are currently available from 5 waves, collected when the children were 9 months, 3 years, 5 years, 7 years and 11 years. The initial MCS sample at wave 1 included 18552 families, another 692 families joined at wave $2 .{ }^{34}$ At wave 5, 13287 families participated (response rate $\left.69 \%\right)^{35}$

\footnotetext{
${ }^{1}$ Department of Epidemiology and Public Health, University College London, London, UK; ${ }^{2}$ Eastman Dental Institute, University College London, London, UK and ${ }^{3}$ Institute of Education, University College London, London, UK. Correspondence: Dr A Heilmann, Department of Epidemiology and Public Health, University College London, 1-19 Torrington Place, London WC1E 7HB, UK.

E-mail: anja.heilmann@ucl.ac.uk

Received 27 July 2016; revised 28 April 2017; accepted 16 May 2017; accepted article preview online 2 June 2017; advance online publication, 27 June 2017
} 
The MCS survey weights include unit non-response weights to adjust for attrition between waves.

Ethical approval has been granted for each sweep of the MCS. For wave 5, ethical approval was granted by the Yorkshire and Humber REC (Ref: $11 / \mathrm{YH} / 0203){ }^{34}$ All participants provided written informed consent.

Outcome variables: BMI, FMI, and overweight at age 11 years The outcome of interest was adiposity (body fatness) at age 11 years, measured via three indicators: BMI, FMI, and overweight. Physical measurements of height, weight and body fat were collected by interviewers who underwent formal training and accreditation. A detailed description of the standardized measurement protocols and process of the interviewer accreditation scheme is available for download from the CLS website. ${ }^{36}$ In brief, children's height was measured using a Leicester Height Measure Stadiometers (Seca, Birmingham, UK), with the child's head in the Frankfurt Plane, and recorded to the nearest completed millimeter. Children were asked to wear only light clothing and to remove shoes and socks as well as hair accessories or hairstyles that could affect the reading. Weight and body fat were measured using calibrated Tanita BF$522 \mathrm{~W}$ scales (Tanita UK, Yiewsley, Middlesex, UK) that were placed on a firm, level surface. We used the derived BMI variable calculated by the CLS. To calculate $\mathrm{FMl}$, we used the following formulas: $\mathrm{FM}=$ weight times percentage of body fat, divided by $100 ; \mathrm{FMI}=\mathrm{FM}$ divided by height squared. BMI and FMI were used as continuous variables. Overweight was a binary variable (non-overweight including healthy weight plus underweight vs overweight including obese), based on the age and sex-specific International Obesity Task Force criteria. ${ }^{37}$

\section{Screen-based media use at age 7 years}

We measured screen-based media use at wave 4/age 7 years because it was the first wave to include information on whether or not the child had a TV in his/her bedroom. Three variables were used to measure children's screen-based media use at age 7 years: whether the child had a bedroom TV; hours spent watching TV or digital versatile disks (DVDs; 'On a normal week day during term time, how many hours does [child] spend watching television, videos or DVDs?' $-<1 \mathrm{~h}, 1-3 \mathrm{~h},>3 \mathrm{~h}$ ); and hours spent playing on the computer ('On a normal weekday during term time, how many hours does [child] spend using a computer or playing electronic games outside school lessons?'-none, $<1 \mathrm{~h}, \geqslant 1 \mathrm{~h}$ ).

\section{Covariates}

The following covariates were included in the fully adjusted models because they are known to be associated with childhood adiposity and might confound the relationship with screen-based media use $\mathrm{e}^{29,38,39}$ : child age, child BMI at wave 2/age 3 years, breastfeeding duration (never, $<4$ months, $\geqslant 4$ months); child ethnicity (White, Mixed, Indian, Pakistani, Bangladeshi, Black Caribbean, Black African, other); maternal BMI at wave 2; maternal education at wave 5 (Level 4/5 (degree or higher degree), Level 3 ( $2+$ A levels), Level 2 ( 5 General Certificate of Secondary Education A-C or $1 \mathrm{~A}$ level), Level $1(<5$ General Certificate of Secondary Education D-E), overseas qualification only, no qualifications); and family income at wave 5 (Organisation for Economic Co-operation and Development equivalized income quintiles, missing data imputed by CLS). Children's BMI at age 3 years was included to minimize the possibility of reverse causation. We chose the earliest possible indicator of child BMI because screen use starts long before age 7 years, and therefore using BMI/FMI from later waves would likely result in overadjustment. Maternal BMI was used as a proxy measure to capture the overall food environment in the household as well as potential genetic influences. Again we wanted to use a measure from the earliest possible time point. Because at wave 1 maternal BMI was still influenced by the recent pregnancy, we used maternal BMI from wave 2 . Breastfeeding duration was included because it follows a strong social gradient and has been linked to a reduced risk of childhood obesity. ${ }^{40}$

As potential mediating variables, we included bedtimes and markers of physical activity at age 7 years. Bedtimes were assessed via the question 'On weekdays during term time, does [child] go to bed at a regular time? What time is that?'. Children were classified as having no fixed bedtime if the answer to the first question was 'no, never or almost never' or 'sometimes', whereas for replies of 'usually' and 'always' bedtimes were coded as follows: 1930 hours or earlier, between 1930 and 2000 hours, between 2000 and 2030 hours, later than 2030 hours. Physical activity outside school lessons was measured using the question 'How many days a week does [child] usually go to a club or class to do sport or any other

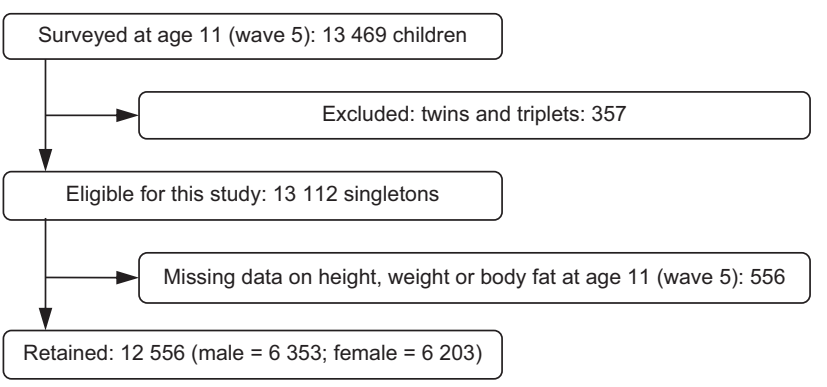

Figure 1. Flow chart of the study participants.

physical activity like swimming, gymnastics, football, dancing, etc.?' Answers were categorized as: $\geqslant 3$ days per week, 2 days per week, 1day per week, or less than once a week.

\section{Study sample}

Of the 13112 children who participated in wave 5 of the MCS and were eligible for this study, 12556 had complete data on all three outcome measures and were included in the analysis sample. We excluded 357 twins and triplets because the examined outcomes are moderated by multiple gestation pregnancies. ${ }^{41} \mathrm{~A}$ flow diagram of the study participants is shown in Figure 1.

Only 8147 children had complete data on all covariates. Missingness was highest for maternal BMI at wave 2 (24\%). Rates of missingness for all variables are shown in Supplementary Table S1 (online Supplementary Appendix). On average, families of children with missing data were more disadvantaged: among children with missing data, $31 \%$ were living in relative poverty (that is, on an income $<60 \%$ of the median of the population) and $36 \%$ of mothers had a university degree, while for those with complete data these were $15 \%$ and $45 \%$, respectively. We therefore used multiple imputation by chained equations to handle missing data on covariates due to item non-response. ${ }^{42}$ Imputations were carried out in Stata version $14.1 .^{43}$ The imputation model included all outcome variables, covariates and MCS design variables. The following were included as auxiliary variables: child BMI and FMI at wave 4/age 7 years; maternal education and family income at wave 4; and maternal BMI at wave 5. Preliminary analyses showed that child gender moderated associations between BMI/FMI and the screen time variables (interaction terms statistically significant). Where interactions are present, the stratify-thenimpute method is recommended as an ideal solution. ${ }^{44}$ We therefore imputed 25 data sets for boys and girls separately. Results from imputed data were largely similar to those obtained from complete case analyses. We report results from analyses of the imputed data.

\section{Statistical analyses}

All analyses were carried out using Stata version 14.1. ${ }^{43}$ MCS survey weights were employed throughout to account for the stratification and geographical clustering of the data and attrition between the MCS waves. Details on response rates and weighting have been reported elsewhere. ${ }^{45}$

After inspecting crude associations between the three outcome measures and explanatory variables, we estimated a series of regression models. For BMI and FMI, multivariable linear regression was used to estimate associations with screen-based media use while adjusting for potential mediating and confounding factors and BMI at age 3 years. For overweight, we used Poisson regression to estimate relative risk (RR). Poisson or log-binomial regression models are preferred for binary outcomes when the outcome is common (prevalence $>10 \%$ ), because in these cases odds ratios obtained from logistic regression can significantly deviate from risk ratios (but are often interpreted as such) and can therefore be misleading. ${ }^{46}$

We present all results stratified by child gender. For each of the three outcome measures (BMI, FMI and overweight), Model 1 included the three screen time variables and child age only. Model 2 further adjusted for child $\mathrm{BMI}$ at age 3 years, breastfeeding duration, child ethnicity, maternal BMI at wave 2 (continuous), maternal education at wave 5 and family income at wave 5 . Model 3 was the fully adjusted model, additionally including bedtime and physical activity at age 7 years. 


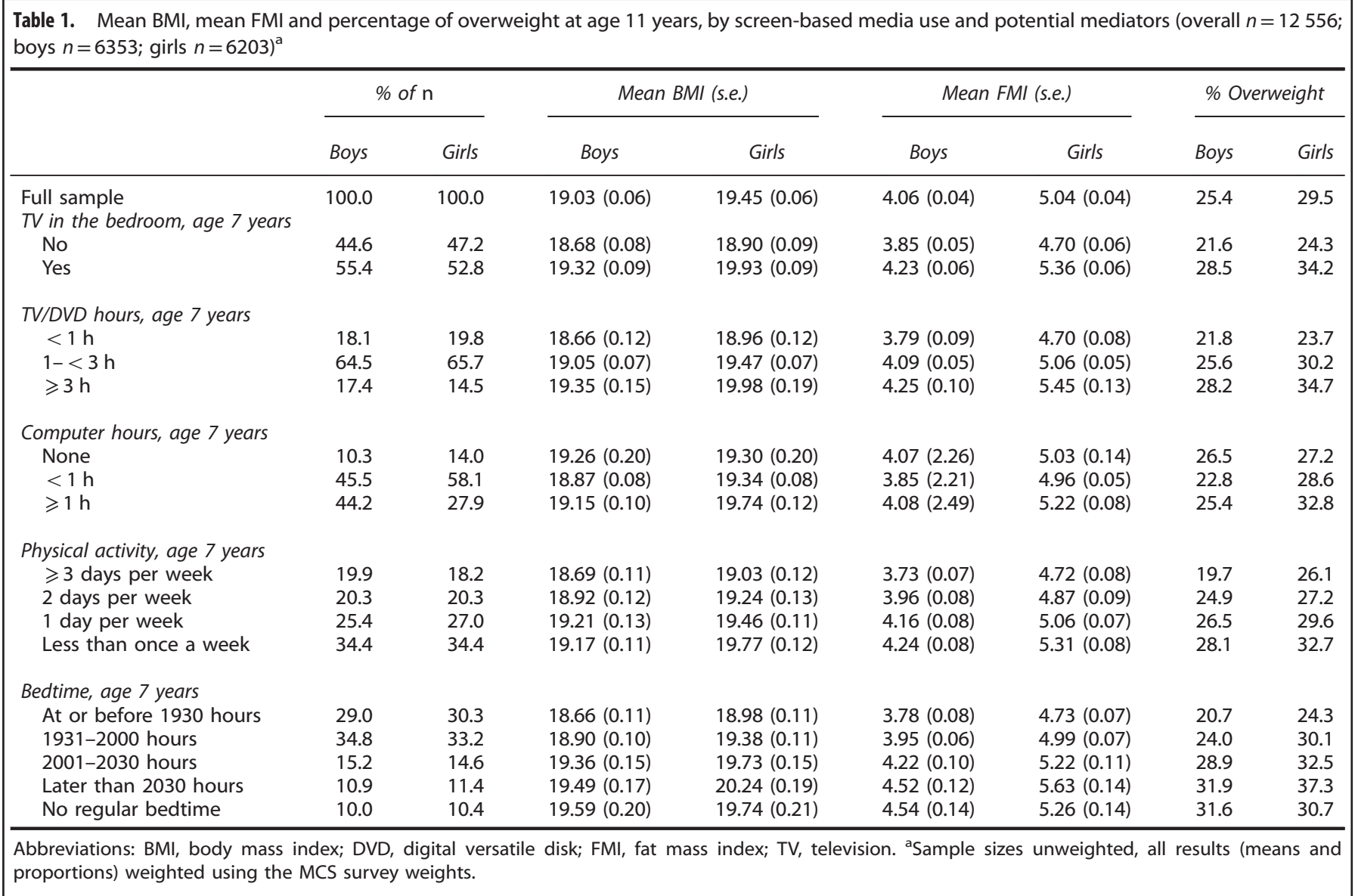

\section{RESULTS}

Sample characteristics

The analyses included 12556 singleton children (6353 boys and 6203 girls) with complete information on the three outcome variables. The unweighted mean age of the analysis sample at wave 5 (when the outcomes were measured) was 11.2 years (s.e. $=0.33$ ), and $50.6 \%$ were boys. The majority of the children were White (84.6\%).

Descriptive statistics are shown in Table 1 and Supplementary Tables S2 and S3 (online Supplementary Appendix). All means and proportions shown in descriptive tables are weighted using MCS survey weights. The mean BMI at age 11 years was 19.0 for boys and 19.5 for girls, while mean FMI was 4.1 for boys and 5.0 for girls. About $25 \%$ of boys and $30 \%$ of girls in the sample were overweight at age 11 years. At age 7 years, 55\% of boys and $53 \%$ of girls had a TV in their bedroom. Average BMI and FMI, as well as prevalence of overweight, were higher among children who had a TV in the bedroom and among children who spent more time watching TV or DVDs at age 7 years (Table 1).

Associations between screen-based media use at age 7 years and adiposity at age 11 years

On average, children who had a TV in the bedroom at age 7 years had a significantly higher BMI and FMI at age 11 years compared with those with no bedroom TV (Model 1 in Table 2). Associations appeared to be stronger for girls than for boys. Associations were attenuated but remained statistically significant following adjustment for covariates (Model 3 in Table 2). Excess BMI was 0.29 (95\% confidence interval $(\mathrm{Cl}) 0.06-0.52)$ for boys and $0.57(95 \% \mathrm{Cl}$ $0.31-0.84)$ for girls; excess FMI was 0.20 (95\% Cl 0.04-0.37) for boys and 0.39 ( $95 \% \mathrm{Cl} 0.21-0.57)$ for girls. Estimates changed very little between Models 2 and 3, suggesting that bedtimes and physical activity did not explain these associations. For boys, hours spent watching TV/DVDs were not associated with BMI and FMI in the adjusted analyses, while for girls, there were statistically significant associations consistent with a dose-response relationship (Models 2 and 3 in Table 2). Again there was only slight attenuation after adjusting for bedtimes and physical activity. Hours spent playing on the computer were not related to BMI or FMI for either gender (Table 2).

Similarly, Poisson regression models (Table 3 ) showed that the RR of being overweight at age 11 years was higher for children who had a TV in their bedroom at age 7 years, compared with those with no bedroom TV. Again associations were somewhat stronger for girls (RR for boys $=1.21,95 \% \mathrm{Cl} 1.07-1.36$; RR for girls $=1.31$, 95\% Cl 1.15-1.48). After adjusting for covariates, TV/DVD hours at age 7 years were related to an increased risk of overweight at age 11 years only for girls, while there was no association among boys (Models 2 and 3 in Table 3). As before, additional adjustment for bedtimes and physical activity did not substantially affect the results. For both genders, computer hours at age 7 years were unrelated to overweight risk at age 11 years.

\section{DISCUSSION}

Our longitudinal analysis has shown that having a TV in the bedroom is an independent risk factor for increased body fatness in this nationally representative sample of UK children. After extensive adjustment for a wide range of covariates, all three measures of body fatness we assessed were associated with having a TV in the child's bedroom. Girls who had a TV in their bedroom at age 7 years were at an approximately 30\% higher risk of being overweight at age 11 years compared with those who did 


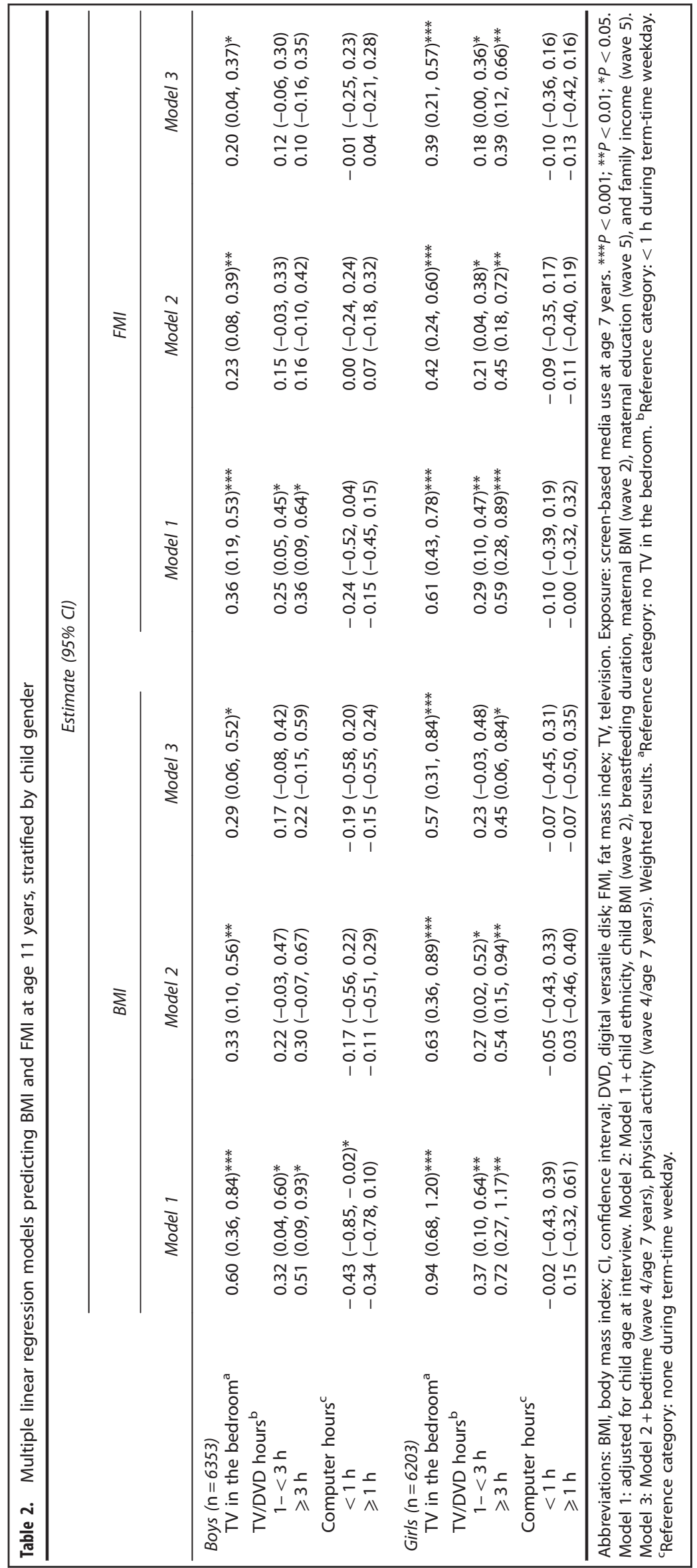


Table 3. Poisson regression models predicting overweight at age 11 years, stratified by child gender

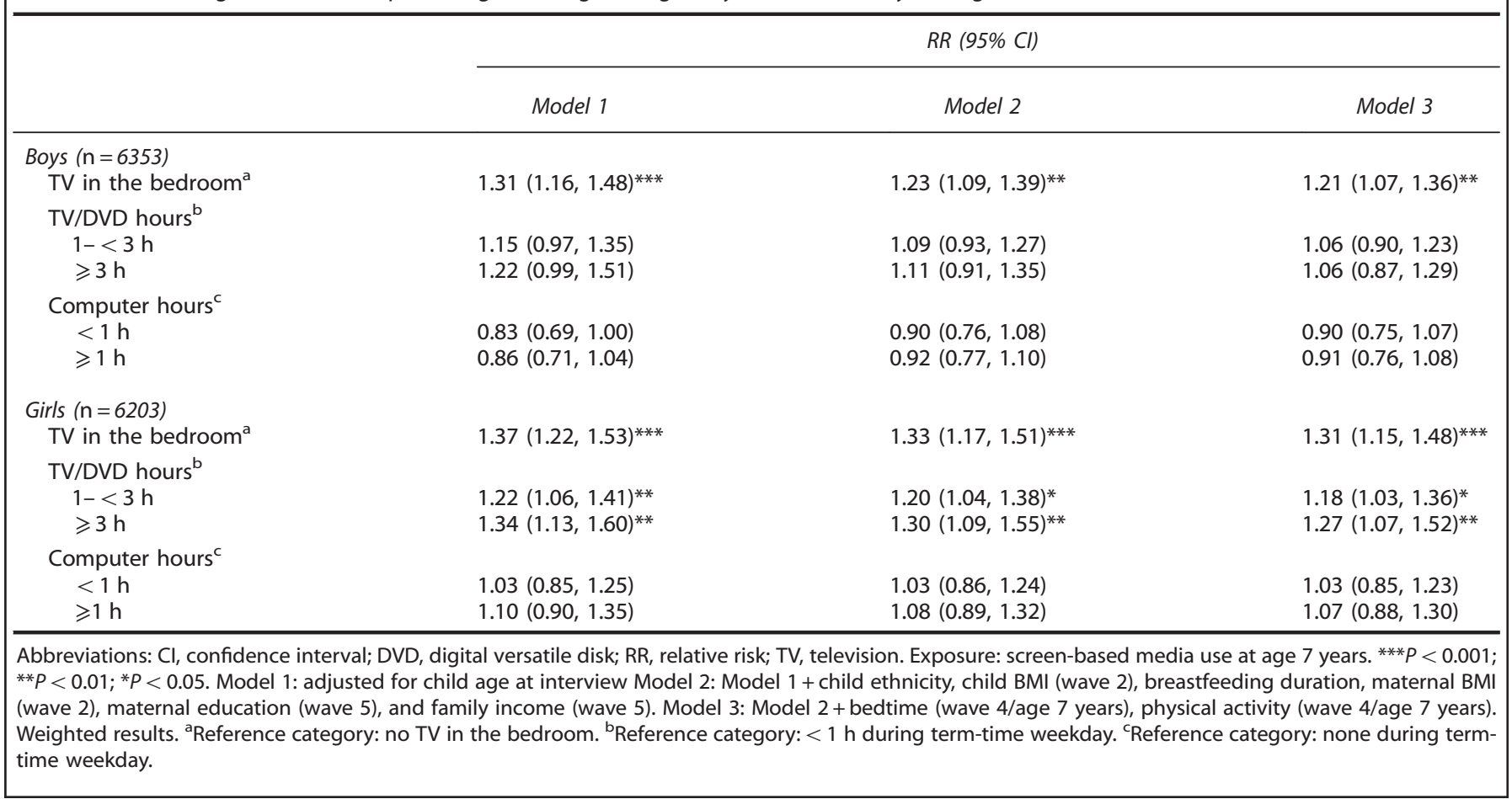

not have a TV in their bedroom, and for boys the risk was increased by about $20 \%$. The effect size of this increased risk of being overweight is comparable to the risks previously identified for physical inactivity and not having been breastfed. ${ }^{40,47}$ The number of hours spent watching TV or DVDs was associated with increased body fatness among girls only, showing a doseresponse relationship. We found no independent association between hours spent using a computer and body fatness for either gender.

That associations between screen use and overweight/obesity are stronger among girls than among boys has been suggested previously ${ }^{13,48,49}$; however, the reasons for these findings remain unclear. Research on the role of children's computer use in the development of overweight/obesity is still sparse and has produced some conflicting findings. ${ }^{10,12,50}$ In our study, computer use was unrelated to later body fatness, which is consistent with the results of one meta-analysis that was, however, conducted $>10$ years ago. ${ }^{12}$ Further good-quality research is clearly needed.

Our results did not support the notion that screen use affects body fatness via reduced sleep, although this finding should be viewed with a degree of caution. Previous research has shown that screen time affects sleep, and shorter sleep duration has been linked to obesity. ${ }^{21-24}$ Children's bedtime, the only measure of sleep available to us, is only an approximation of sleep duration and quality, which might have precluded us from finding evidence for a role of sleep in the association between bedroom TVs and body fatness. In relation to physical activity, the available measures in the MCS are also relatively crude; however, our results are consistent with the findings of three systematic reviews which concluded that sedentary behaviors such as watching TV do not necessarily displace physical activity. ${ }^{12,27,28}$

More than half of the 7-year-olds in our sample had a TV in their bedroom. This finding is well in line with other recent UK reports on children's media use, which also suggest that children increasingly use portable devices, such as tablets and laptops in their bedrooms. ${ }^{2,3}$
This analysis has some limitations. First, our measures of children's screen time relied on parental reports. Parents are likely to underestimate the hours children spend using a screen, especially where the child has access to it in their own room. On the other hand, the question whether the child has a TV in their bedroom is straightforward and measurement error for this variable is unlikely to be a concern. Second, owing to the very limited availability of good quality dietary data in the MCS, we were unable to explore whether diet patterns were on the pathway between screen time and body fatness. It is important, however, to acknowledge the strengths of our study. Our longitudinal analysis was conducted on a nationally representative large sample of children from across the United Kingdom, who were followed over a 4-year time period from age 7 to age 11 years. We controlled for a wide range of covariates, including the child's BMI at age 3 years and maternal BMI, thus minimizing the possibility of reverse causation and accounting for the influence of genetic as well as environmental factors. We measured body fatness using three different indicators: BMI, FMl, and overweight. The inclusion of the FMI improves on previous research that relied mainly on BMI, as FMI represents a more objective index of adiposity that is independent of lean body mass. ${ }^{33,51}$ Having said that, our findings were consistent across the three outcome measures, and conclusions were very similar irrespective of whether BMI or FMI was used to measure body fatness. Our data therefore provide some evidence that studies using only BMI to assess associations between screen use and body fatness can produce equally informative results.

In conclusion, we have shown that having a TV in a child's bedroom is a significant independent risk factor for overweight and increased body fatness in a nationally representative sample of UK children. Although our analysis is not causal, our results indicate that future childhood obesity prevention strategies should consider access to TVs in children's bedrooms as a risk factor for obesity. Future research should investigate potential pathways via sleep duration and diet, examine differences 
between boys and girls in more depth and utilize interventional designs. Also, further research is needed among older children and adolescents, as the use of screen-based media, including computers, mobile phones and tablets, increases with age.

\section{CONFLICT OF INTEREST}

Professor Fitzsimons is the Principal Investigator of the Millennium Cohort Study, the data set used in this paper. However, this role is independent of the analysis presented in this paper. The other authors declare no conflict of interest.

\section{ACKNOWLEDGEMENTS}

We acknowledge funding from the Economic and Social Research Council, grant number ES/G040923/1, for this work. Professor Kelly is in receipt of a grant from the UK Economic and Social Research Council during the conduct of the study.

\section{AUTHOR CONTRIBUTIONS}

AH co-designed the study, conducted the analyses, interpreted the results, drafted the initial manuscript, critically reviewed and revised the manuscript and approved the final manuscript as submitted. PR carried out the initial analyses, interpreted the results, critically reviewed and revised the manuscript and approved the final manuscript as submitted. EF secured funding and codesigned the study, provided analytical support, interpreted the results, critically reviewed and revised the manuscript and approved the final manuscript as submitted. YK co-designed the study, provided analytical support, interpreted the results, critically reviewed and revised the manuscript and approved the final manuscript as submitted. RW conceived the research question, co-designed the study, interpreted the results, drafted the initial manuscript, critically reviewed and revised the manuscript, and approved the final manuscript as submitted.

\section{REFERENCES}

1 Houghton S, Hunter SC, Rosenberg M, Wood L, Zadow C, Martin K et al. Virtually impossible: limiting Australian children and adolescents daily screen based media use. BMC Public Health 2015; 15: 1-11.

2 OfCom. Children and parents: media use and attitudes report 2011.

3 OfCom. Children and parents: media use and attitudes report 2016.

4 Johnson W, Li L, Kuh D, Hardy R. How has the age-related process of overweight or obesity development changed over time? Co-ordinated analyses of individual participant data from five United Kingdom birth cohorts. PLoS Med 2015; 12 : e1001828.

5 Health and Social Care Information Centre. National Child Measurement Programme, England-2014/15 school year 2015.

6 Gortmaker SL, Must A, Sobol AM, Peterson K, Colditz GA, Dietz WH. Television viewing as a cause of increasing obesity among children in the United States, 1986-1990. Arch Pediatr Adolesc Med 1996; 150: 356-362.

7 Kaur H, Choi WS, Mayo MS, Jo Harris K. Duration of television watching is associated with increased body mass index. J Pediatr 2003; 143: 506-511.

8 Dennison BA, Erb TA, Jenkins PL. Television viewing and television in bedroom associated with overweight risk among low-income preschool children. Pediatrics 2002; 109: 1028-1035.

9 Danner FW. A National Longitudinal Study of the association between hours of TV viewing and the trajectory of BMI growth among US children. J Pediatr Psychol 2008; 33: 1100-1107.

10 de Jong E, Visscher TLS, HiraSing RA, Heymans MW, Seidell JC, Renders CM. Association between TV viewing, computer use and overweight, determinants and competing activities of screen time in 4- to 13-year-old children. Int $J$ Obes 2013; 37: 47-53.

11 Tremblay MS, LeBlanc AG, Kho ME, Saunders TJ, Larouche R, Colley RC et al. Systematic review of sedentary behaviour and health indicators in school-aged children and youth. Int J Behav Nutr Phys Act 2011; 8: 1-22.

12 Marshall SJ, Biddle SJH, Gorely T, Cameron N, Murdey I. Relationships between media use, body fatness and physical activity in children and youth: a meta-analysis. Int J Obes Relat Metab Disord 2004; 28: 1238-1246.

13 Braithwaite I, Stewart AW, Hancox RJ, Beasley R, Murphy R, Mitchell EA et al. The worldwide association between television viewing and obesity in children and adolescents: cross sectional study. PLoS One 2013; 8: e74263.
14 Sisson SB, Broyles ST, Newton Jr RL, Baker BL, Chernausek SD. TVs in the bedrooms of children: does it impact health and behavior? Prev Med 2011; 52: 104-108.

15 Gilbert-Diamond D, Li Z, Adachi-Mejia AM, McClure AC, Sargent JD. Association of a television in the bedroom with increased adiposity gain in a nationally representative sample of children and adolescents. JAMA Pediatr 2014; 168: 427-434.

16 Dennison BA, Edmunds LS. The role of television in childhood obesity. Prog Pediatr Cardiol 2008; 25: 191-197.

17 Coon KA, Tucker KL. Television and children's consumption patterns. A review of the literature. Minerva Pediatr 2002; 54: 423-436.

18 Francis LA, Birch LL. Does eating during television viewing affect preschool children's intake? J Am Diet Assoc 2006; 106: 598-600.

19 Marsh S, Ni Mhurchu C, Jiang Y, Maddison R. Comparative effects of TV watching, recreational computer use, and sedentary video game play on spontaneous energy intake in male children. A randomised crossover trial. Appetite 2014; 77: 13-18.

20 Wiecha JL, Peterson KE, Ludwig DS, Kim J, Sobol A, Gortmaker SL. When children eat what they watch: impact of television viewing on dietary intake in youth. Arch Pediatr Adolesc Med 2006; 160: 436-442.

21 Hale L, Guan S. Screen time and sleep among school-aged children and adolescents: a systematic literature review. Sleep Med Rev 2015; 21: 50-58.

22 Cappuccio FP, Taggart FM, Kandala N-B, Currie A, Peile E, Stranges S et al. Metaanalysis of short sleep duration and obesity in children and adults. Sleep 2008; 31: 619-626.

23 Patel SR, Hu FB. Short sleep duration and weight gain: a systematic review. Obesity (Silver Spring, Md) 2008; 16: 643-653.

24 Magee C, Caputi P, Iverson D. Lack of sleep could increase obesity in children and too much television could be partly to blame. Acta Paediatr 2014; 103: e27-e31.

25 Cespedes EM, Gillman MW, Kleinman K, Rifas-Shiman SL, Redline S, Taveras EM. Television viewing, bedroom television, and sleep duration from infancy to mid-childhood. Pediatrics 2014; 133: e1163-e1171.

26 Andersen RE, Crespo CJ, Bartlett SJ, Cheskin LJ, Pratt M. Relationship of physical activity and television watching with body weight and level of fatness among children: results from the Third National Health and Nutrition Examination Survey. JAMA 1998; 279: 938-942.

27 Rey-López JP, Vicente-Rodríguez G, Biosca M, Moreno LA. Sedentary behaviour and obesity development in children and adolescents. Nutr Metab Cardiovasc Dis 2008; 18: 242-251.

28 Pearson N, Braithwaite RE, Biddle SJH, van Sluijs EMF, Atkin AJ. Associations between sedentary behaviour and physical activity in children and adolescents: a meta-analysis. Obes Rev 2014; 15: 666-675.

29 Goisis A, Sacker A, Kelly Y. Why are poorer children at higher risk of obesity and overweight? A UK cohort study. Eur J Public Health 2016; 26: 7-13.

30 Hawkins SS, Cole TJ, Law C, The Millennium Cohort Study Child Health Group. An ecological systems approach to examining risk factors for early childhood overweight: findings from the UK Millennium Cohort Study. J Epidemiol Community Health 2009; 63: 147-155.

31 Griffiths LJ, Hawkins SS, Cole TJ, Dezateux C. Risk factors for rapid weight gain in preschool children: findings from a UK-wide prospective study. Int J Obes 2010; 34: 624-632.

32 Brophy S, Cooksey R, Gravenor MB, Mistry R, Thomas N, Lyons RA et al. Risk factors for childhood obesity at age 5: analysis of the Millennium Cohort Study. BMC Public Health 2009; 9: 1-7.

33 Wells JC, Williams JE, Chomtho S, Darch T, Grijalva-Eternod C, Kennedy K et al. Body-composition reference data for simple and reference techniques and a 4component model: a new UK reference child. Am J Clin Nutr 2012; 96: 1316-1326.

34 Hansen K. Millennium Cohort Study: A Guide to the Datasets. 8th edn. Centre for Longitudinal Studies, University of London: London, UK, 2014.

35 Mostafa T. Technical Report on Response in Sweep 5 (Age 11). Centre for Longitudinal Studies, University of London: London, UK, 2014.

36 Calderwood L, Smith K, Rose N, Williams R. Training and Accreditation of Interviewers to Carry Out Physical Measurements on the UK Millennium Cohort Study. Centre for Longitudinal Studies, University of London: London, UK, 2014.

37 Cole TJ, Bellizzi MC, Flegal KM, Dietz WH. Establishing a standard definition for child overweight and obesity worldwide: international survey. BMJ 2000; 320: 1240-1243.

38 Weng SF, Redsell SA, Swift JA, Yang M, Glazebrook CP. Systematic review and meta-analyses of risk factors for childhood overweight identifiable during infancy. Arch Dis Child 2012; 97: 1019-1026.

39 Zilanawala A, Davis-Kean P, Nazroo J, Sacker A, Simonton S, Kelly Y. Race/ethnic disparities in early childhood BMI, obesity and overweight in the United Kingdom and United States. Int J Obes (Lond) 2015; 39: 520-529.

40 Horta BL, Loret de Mola C, Victora CG. Long-term consequences of breastfeeding on cholesterol, obesity, systolic blood pressure and type 2 diabetes: a systematic review and meta-analysis. Acta Paediatr 2015; 104: 30-37. 
41 The ESHRE Capri Workshop Group. Multiple gestation pregnancy. Hum Reprod 2000; 15: 1856-1864.

42 Allison P. Missing data: quantitative applications in the social sciences. Br J Math Stat Psychol 2002; 55: 193-196.

43 Statacorp. Stata Statistical Software: Release 14. StataCorp LP: College Station, TX, USA, 2015.

44 Von Hippel PT. How to impute interactions, squares, and other transformed variables. Sociol Methodol 2009; 39: 265-291.

45 Plewis I. The Millennium Cohort Study: Technical Report on Sampling. Centre for Longitudinal Studies, University of London: London, UK, 2007.

46 Barros A, Hirakata V. Alternatives for logistic regression in cross-sectional studies: an empirical comparison of models that directly estimate the prevalence ratio. BMC Med Res Methodol 2003; 3: 1-13.

47 Janssen I, LeBlanc AG. Systematic review of the health benefits of physical activity and fitness in school-aged children and youth. Int J Behav Nutr Phys Act 2010; 7: 40 .

48 Hancox RJ, Poulton R. Watching television is associated with childhood obesity: but is it clinically important? Int J Obes (Lond) 2006; 30: 171-175.

49 Crespo CJ, Smit E, Troiano RP, Bartlett SJ, Macera CA, Andersen RE. Television watching, energy intake, and obesity in US children: results from the third
National Health and Nutrition Examination Survey, 1988-1994. Arch Pediatr Adolesc Med 2001; 155: 360-365.

50 Kautiainen S, Koivusilta L, Lintonen T, Virtanen SM, Rimpela A. Use of information and communication technology and prevalence of overweight and obesity among adolescents. Int J Obes Relat Metab Disord 2005; 29: 925-933.

51 Weber DR, Moore RH, Leonard MB, Zemel BS. Fat and lean BMI reference curves in children and adolescents and their utility in identifying excess adiposity compared with BMI and percentage body fat. Am J Clin Nutr 2013; 98: 49-56.

(i) This work is licensed under a Creative Commons Attribution 4.0 International License. The images or other third party material in this article are included in the article's Creative Commons license, unless indicated otherwise in the credit line; if the material is not included under the Creative Commons license, users will need to obtain permission from the license holder to reproduce the material. To view a copy of this license, visit http://creativecommons.org/licenses/ by/4.0/

(c) The Author(s) 2017

Supplementary Information accompanies this paper on International Journal of Obesity website (http://www.nature.com/ijo) 